\title{
Binding and functional properties of the novel somatostatin analogue KE 108 at native mouse somatostatin receptors
}

\author{
Davide Cervia $^{\mathrm{a}, *}$, Daniel Langenegger ${ }^{\mathrm{b}}$, Edi Schuepbach ${ }^{\mathrm{b}}$, Maurizio Cammalleri ${ }^{\mathrm{a}}$, \\ Philippe Schoeffter ${ }^{\mathrm{b}}$, Herbert A. Schmid ${ }^{\mathrm{c}}$, Paola Bagnoli ${ }^{\mathrm{a}}$, Daniel Hoyer ${ }^{\mathrm{b}, \mathrm{d}}$ \\ aDipartimento di Fisiologia e Biochimica "G. Moruzzi”, Università di Pisa, 56127 Pisa, Italy \\ ${ }^{\mathrm{b}}$ Neuroscience Research, Novartis Institutes for Biomedical Research, Novartis Pharma AG, 4002 Basel, Switzerland \\ ${ }^{\mathrm{c} O n c o l o g y}$ Research, Novartis Institutes for Biomedical Research, Novartis Pharma AG, 4002 Basel, Switzerland \\ ${ }^{\mathrm{d}}$ The Harold L. Dorris Neurological Research Center, Department of Neuropharmacology, The Scripps Research Institute, \\ La Jolla, CA 92037, USA
}

Received 1 September 2004; received in revised form 14 December 2004; accepted 21 December 2004

\begin{abstract}
Clinically used somatostatin (SRIF) analogs, octreotide and lanreotide, act primarily by binding to SRIF receptor subtype 2 $\left(\mathrm{sst}_{2}\right)$. In contrast, the recently described multiligand SOM230 binds with high affinity to sst ${ }_{1-3}$ and sst ${ }_{5}$ and $\mathrm{KE}_{108}$ is characterised as a high affinity ligand for all five SRIF receptors. In tumoural mouse corticotrophs (AtT-20 cells) and in mouse hippocampus, binding and functional features of KE 108 were examined and compared to SRIF-14, octreotide and SOM230. In AtT-20 cells, KE 108 bound with high affinity at ${ }^{125}$ I]LTT-SRIF-28-labelled sites similarly to SRIF-14, octreotide and SOM230. At the functional level, all four ligands increased guanosine-5'-O-(3-[ $\left[{ }^{35} \mathrm{~S}\right]$ thio $)$-triphosphate binding and decreased cAMP accumulation or intracellular $\mathrm{Ca}^{2+}$ concentration through $\mathrm{G}_{\mathrm{i} / \mathrm{o}}$ proteins. In hippocampal slices, KE 108, octreotide and SOM230 also bound with high affinity at $\left[{ }^{125}\right.$ I]LTT-SRIF-28-labelled sites similarly to SRIF-14, but KE 108, octreotide or SOM230 did not influence spontaneous epileptiform activity which was, in contrast, inhibited by SRIF-14. In conclusion, this study demonstrates that KE 108 has high affinity for native mouse SRIF receptors. Functionally, KE 108 mediates SRIF action at sst $2 / 5$ in corticotrophs whereas it does not mimic the SRIF-induced inhibition of hippocampal excitation suggesting that the high potency and efficacy of a synthetic ligand to all known SRIF receptors may not reproduce entirely the effects of the natural SRIF.
\end{abstract}

(C) 2005 Elsevier Ltd. All rights reserved.

Keywords: Somatostatin agonists; AtT-20 cells; Mouse hippocampus; Receptor binding; cAMP; $\mathrm{Ca}^{2+}$ regulation; Epilepsy

\section{Introduction}

Somatostatin (SRIF: somatotropin-release inhibiting factor) is a cyclic peptide that exists in two biologically active forms, SRIF-14 and SRIF-28, which have been linked to a number of pathologies, e.g. acromegaly, gastrointestinal disorders, tumours in addition to various

\footnotetext{
* Corresponding author. Tel.: +39050 2213459; fax: +39050 2213527.

E-mail address: d.cervia@dfb.unipi.it (D. Cervia).
}

psychiatric or neurological diseases, e.g. epilepsy, depression, schizophrenia and dementias. SRIFs are predominantly produced by normal endocrine, gastrointestinal and immune cells, as well as by certain tumours (Weckbecker et al., 2003). SRIFs are also present in numerous neuronal cells throughout the brain, including the hypothalamus and the hippocampal formation (Binaschi et al., 2003; Olias et al., 2004). SRIF actions are mediated by five receptors $\left(\mathrm{sst}_{1-5}\right)$ that are coupled to $G$ proteins, and trigger multiple transmembrane signalling systems (Lahlou et al., 2004). 